\title{
Furoquinoline Alkaloids and Methoxyflavones from the Stem Bark of Melicope madagascariensis (Baker) T.G. Hartley
}

\author{
Vincent E. Rasamison · Peggy J. Brodie • \\ Emilio F. Merino • Maria B. Cassera • \\ Michel A. Ratsimbason • Stephan Rakotonandrasana • \\ Andriamalala Rakotondrafara $\cdot$ Elie Rafidinarivo • \\ David G. I. Kingston · Harinantenaina L. Rakotondraibe
}

Received: 30 June 2016/Accepted: 30 August 2016/Published online: 21 September 2016

(C) The Author(s) 2016. This article is published with open access at Springerlink.com

\begin{abstract}
Melicope madagascariensis (Rutaceae) is an endemic plant species of Madagascar that was first classified as a member of the genus Euodia J. R. \& G. Forst (Rutaceae) under the scientific name Euodia madagascariensis Baker. Based on morphological characteristics, Thomas Gordon Hartley taxonomically revised E. madagascariensis Baker to be $M$. madagascariensis (Baker) T.G. Hartley. Chemotaxonomical studies have long been used to help the identification and confirmation of taxonomical classification of plant species and botanicals. Aiming to find more evidences to support the taxonomical revision performed on E. madagascariensis, we carried out phytochemical investigation of two samples of the plant. Fractionation of the ethanol extracts prepared from two stem bark samples of M. madagascariensis (Baker) T.G. Hartley led to the isolation of seven known furoquinoline alkaloids 1-7 and two known methoxyflavones 8 and 9. The presence of furoquinoline alkaloids and methoxyflavones in the title species is in agreement with its taxonomic transfer from Euodia to Melicope. Antiprotozoal evaluation of the isolated compounds showed that 6-methoxy-7-hydroxydictamnine (heliparvifoline, 3) showed weak antimalarial activity $\left(\mathrm{IC}_{50}=35 \mu \mathrm{M}\right)$ against the chloroquine-resistant strain $\mathrm{Dd} 2$ of Plasmodium falciparum. Skimmianine (4) displayed moderate cytotoxicity with $\mathrm{IC}_{50}$ value of $1.5 \mu \mathrm{M}$ against HT29 colon cancer cell line whereas 3,5-dihydroxy-3', $4^{\prime}, 7$-trimethoxyflavone (9) was weakly active in the same assay $\left(\mathrm{IC}_{50}=13.9 \mu \mathrm{M}\right)$.
\end{abstract}

The botanical collection in Madagascar was carried out under a benefit-sharing agreement between all the parties involved, and under the authority of plant collection and extract export permits issued by the government of Madagascar.

\footnotetext{
V. E. Rasamison - M. A. Ratsimbason - S. Rakotonandrasana · A. Rakotondrafara

Centre National d'Application de Recherches Pharmaceutiques, B.P. 702, 101 Antananarivo, Madagascar

P. J. Brodie · D. G. I. Kingston

Department of Chemistry and the Virginia Tech Center for Drug Discovery, M/C 0212, Virginia Tech, Blacksburg, VA 24061, USA

E. F. Merino - M. B. Cassera

Department of Biochemistry and the Virginia Tech Center for Drug Discovery, M/C 0308, Virginia Tech, Blacksburg,

VA 24061, USA
}

\author{
E. Rafidinarivo \\ Institut Supérieur de Technologie, B.P. 8122, 101 Antananarivo, \\ Madagascar \\ H. L. Rakotondraibe ( $\square)$ \\ Division of Medicinal Chemistry and Pharmacognosy, College \\ of Pharmacy, The Ohio State University, Columbus, OH 43210, \\ USA \\ e-mail: rakotondraibe.1@osu.edu
}




\section{Graphical Abstract}
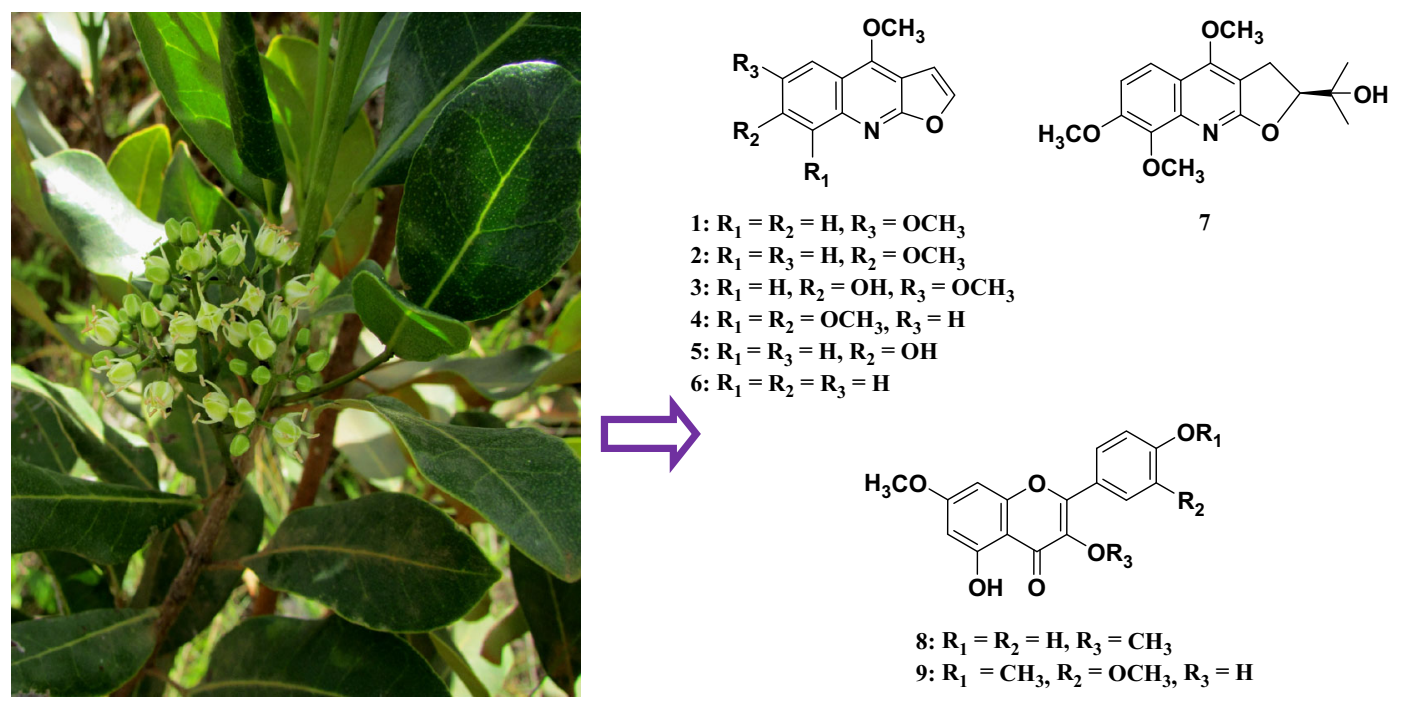

Keywords Chemotaxonomy · Furoquinoline alkaloids - Methoxyflavones · Antimalarial activity · Cytotoxicity - Melicope madagascariensis (Rutaceae)

\section{Introduction}

The genus Melicope J. R. \& G. Forst (Rutaceae) comprises about 235 species distributed in the Madagascar and Mascarenes islands and Indo-Himalaya regions in the Hawaii and Marquesas islands to New Zealand. Melicope madagascariensis (Baker) T.G. Hartley is an endemic species to Madagascar, which has long been classified in the genus Euodia J. R. \& G. Forst (Rutaceae) under the scientific name Euodia madagascariensis Baker before being assigned to the genus Melicope. This taxonomic revision introduced by Hartley in 2001 was based on morphological characteristics and concerned the other Madagascan plant species that were placed in the genus Euodia [1].

M. madagascariensis is a tree up to $10-20 \mathrm{~m}$ tall which is encountered in the rainforest of Madagascar and is traditionally employed as exhilarating agent, purgative, and in formulations for the treatment of liver, kidney and stomach disorders, bronchitis and mumps [2]. Members of the genus Melicope are rich sources of furoquinoline alkaloids, methoxyflavones and acetophenones, some of which have elicited antiplatelet aggregation [3], cytotoxic [4] and antimalarial activities [5]. A previous phytochemical study on M. madagascariensis reported the isolation of methoxyflavones [6], a class of compounds that have also been found in Euodia species already transferred into Melicope. As part of our ongoing projects aiming to characterize secondary metabolites of plants originated from Madagascar rainforest for biological and chemotaxonomical studies, we carried out phytochemical investigation of $M$. madagascariensis, which is one of the eleven Melicope species endemic to Madagascar. This paper deals with the isolation of nine known compounds including seven furoquinoline alkaloids 1-7 and two methoxyflavones 8 and 9 from two samples of the stem bark of this species. Herein, we discuss the chemotaxonomic significance as well as the antimalarial and cytotoxic activities of the isolated compounds.

\section{Results and Discussion}

A stem bark sample of $M$. madagascariensis was collected from Zahamena, Madagascar. Its ethanol extract (MG250) was first subjected to a modified Kupchan partitioning to give hexane-soluble, chloroform $\left(\mathrm{CHCl}_{3}\right)$-soluble and aqueous $\mathrm{MeOH}$-soluble extracts. Fractionation of the $\mathrm{CHCl}_{3}$-soluble extract by successive open column chromatography over Sephadex LH-20 and silica gel yielded three furoquinoline alkaloids, pteleine (1) [7], evolitrine (2) [7] and 6-methoxy-7-hydroxydictamnine (heliparvifoline, 3) $[8]$.

Further phytochemical investigation of the same plant was conducted on a larger collection of stem bark (ST1375) samples collected from Moramanga, 
Madagascar. Fractionation of the ethanol extract of ST1375 was first carried out by performing selective isolation of alkaloids through conventional acid-base treatment of the $\mathrm{CHCl}_{3}$-soluble extract obtained from the same method as above, to finally provide basic and neutral fractions. Subsequent separations of these two fractions by a combination of chromatography techniques (Column Chromatography, HPLC and preparative TLC) yielded four furoquinoline alkaloids identified as: skimmianine (4) [9], confusameline (5) [10], dictamnine (6) [7] and 7,8-dimethoxyplatydesmine (7) [11], and two methoxyflavones, kumatakenin (8) [12] and 3,5-dihydroxy-3',4',7-trimethoxyflavone (9) [12]. This is the first report of the isolation of compounds 1-9 (Fig. 1) from M. madagascariensis. Except the 3,5dihydroxy-3', $4^{\prime}, 7$-trimethoxyflavone (9), all the other compounds isolated in the present work have been already encountered in other Melicope species, such as M. semecarpifolia and M. pteleifolia [3, 13].

With the exception of few species including those of the genus Euodia, furoquinoline alkaloids are widespread in the Rutaceae family [14]. In particular, a number of furoquinoline alkaloids and derivatives have been reported from species of the genus Melicope [3, 15, 16]. The isolation of furoquinoline alkaloids from M. madagascariensis chemotaxonomically confirmed the classification of the present plant species in the genus Melicope of the Rutaceae family. Furthermore, polyoxygenated flavones (polymethoxy and methylenedioxy) have been considered to be characteristic chemical components of plant species of the genus Melicope inside the Rutaceae family [17]. The isolation of furoquinoline alkaloids and methoxylated flavones from the present plant species is in good agreement with its taxonomic reassignment from Euodia into Melicope. This study added one more species to the Melicopeproducing methoxyflavones. Whether all of the Euodia species containing furoquinoline alkaloids and methoxyflavones should be moved to the genus Melicope or not is one of the major questions that can be unfolded from the present investigation. Apart from the morphological and phytochemical contributions, full genome sequencing of all species of the genus to be transferred would complete this taxonomical classification.

The sample MG250 was collected for the International Cooperative Biodiversity Group (ICBG)/Madagascar program that was mainly aimed at searching for antimalarial and antiproliferative agents from natural resources from Madagascar. Evaluation of compounds 1-3 for their antimalarial activity against the multidrug-resistant strain Dd2 of Plasmodium falciparum showed that only heliparvifoline (3) exhibited growth inhibitory effect at relatively high concentration $\left(\mathrm{IC}_{50}=35 \mu \mathrm{M}\right)$. Positive control consisted of fosmidomycin $\left(\mathrm{IC}_{50}=0.31 \mu \mathrm{M}\right)$. Moreover, in vitro antimalarial activity against the chloroquine-susceptible HB3 (Honduras) and the chloroquine resistant W-2 (Indochina) strains of $P$. falciparum has been previously performed on some Rutaceous furoquinoline alkaloids such as skimmianine (4), haplopine (10), kokusaginine (11), acronycidine (12) and acronydine (13) [18]. Although the compounds isolated in the present study did not exhibit strong antimalarial activity against the multidrug-resistant strain Dd2 of Plasmodium falciparum, the present paper added more data on the antimalarial activity of furoquinoline alkaloids of Rutaceous plants. In addition, compounds 4-9 isolated from the sample ST1375 were assayed against the human colorectal adenocarcinoma (HT-29) cell line. As results, compounds 5-8 were inactive in this assay while skimmianine (4) and 3,5-dihydroxy-3', 4',7-trimethoxyflavone (9) exhibited moderate and weak activity with $\mathrm{IC}_{50}$ values of $1.5 \mu \mathrm{M}$ and $13.9 \mu \mathrm{M}$, respectively.

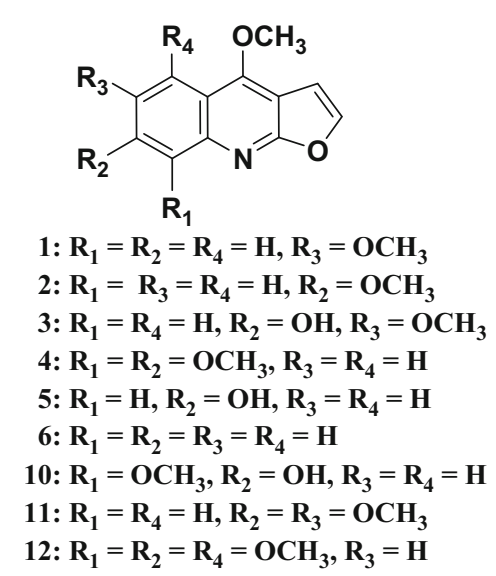

Fig. 1 Structures of compounds 1-13
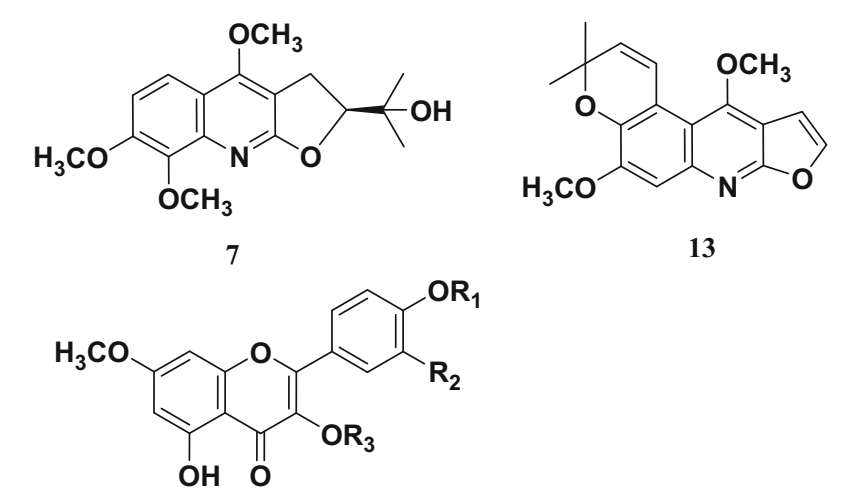

8: $\mathbf{R}_{1}=\mathbf{R}_{2}=\mathrm{H}, \mathbf{R}_{3}=\mathrm{CH}_{3}$ 9: $\mathrm{R}_{1}=\mathrm{CH}_{3}, \mathrm{R}_{\mathbf{2}}=\mathrm{OCH}_{3}, \mathrm{R}_{3}=\mathrm{H}$ 


\section{Conclusions}

The current study extends the knowledge about the chemistry of $M$. madagascariensis. The presence of furoquinoline alkaloids and methoxylated flavones in this plant provides support to its re-classification from the genus Euodia to Melicope. Heliparvifoline (3) displayed weak antimalarial activity $\left(\mathrm{IC}_{50}=35 \mu \mathrm{M}\right)$ against strain $\mathrm{Dd} 2$ of $P$. falciparum whereas skimmianine (4) and 3,5-dihydroxy$3^{\prime}, 4^{\prime}, 7$-trimethoxyflavone (9) were identified as the most cytotoxic constituents against HT-29 colon cancer line.

\section{Experimental Section}

\subsection{General Experimental Procedures}

${ }^{1} \mathrm{H}$ NMR spectra were recorded on Bruker Avance 400 and 500 spectrometers in $\mathrm{CDCl}_{3}$ or $\mathrm{CD}_{3} \mathrm{OD}$ with TMS as internal standard. Semi-preparative HPLC was performed on a Shimadzu instrument consisting of LC-20AB pump, SPD-20A Prominence detector and CBM-20Alite system controller. Sephadex LH-20 (Sigma), silica gel 60 (EMD Chemicals, $0.04-0.063 \mathrm{~mm}$ ) and $\mathrm{C} 18$ reversed phase silica gel (EMD Chemicals, 0.04-0.063 mm) were used for column chromatography.

\subsection{Antimalarial Assay}

The antimalarial assay was carried out at Virginia Tech against the multidrug-resistant strain $\mathrm{Dd} 2$ of $P$. falciparum by using the SYBR Green I-based plate assay as previously reported [19].

\subsection{Cytotoxicity Assay}

Cytotoxicity assay against HT-29 human colon cancer cell line was performed at the College of Pharmacy, The Ohio State University, USA by using a sulforhodamine B reduction assay procedure as described in a previous paper [20].

\subsection{Plant Material}

The first sample coded MG250 of M. madagascariensis stem bark was collected in February 2000 from plants growing in the forest adjacent to the Zahamena National Park. A larger collection of the same plant material designated ST1375 was conducted in November 2009 in the Antsasaka forest of Moramanga. These two collection sites were about $250 \mathrm{~km}$ distant from each other in the Atsinanana region of Madagascar. Voucher specimens have been deposited at the herbarium of the Centre National d'Application de Recherches Pharmaceutiques (CNARP),
Antananarivo, Madagascar under the codes RJO157 for MG250 and ST1375 B for ST1375.

\subsection{Extraction and Isolation}

The dried and powdered sample MG250 (300 g) was macerated in EtOH for $48 \mathrm{~h}$ to yield $11.5 \mathrm{~g}$ of a crude $\mathrm{EtOH}$ extract. A portion $(1.5 \mathrm{~g})$ was suspended in $90 \%$ aqueous $\mathrm{MeOH}(150 \mathrm{~mL})$ and extracted with $n$-hexane $(3 \times 200 \mathrm{~mL}$ portions). The aqueous $\mathrm{MeOH}$ layer was then diluted to $60 \%$ aqueous $\mathrm{MeOH}$ by addition of water before partitioning with $\mathrm{CHCl}_{3}(3 \times 200 \mathrm{~mL}$ portions $)$. Finally, the aqueous $\mathrm{MeOH}$ phase was vacuum concentrated, suspended in $\mathrm{H}_{2} \mathrm{O}(75 \mathrm{~mL})$ and extracted with $n$-BuOH saturated with water $(3 \times 75 \mathrm{~mL}$ portions). Elimination of all the solvents in vacuo provided dried $n$-hexane soluble fraction $(143.5 \mathrm{mg})$, $\mathrm{CHCl}_{3}$-soluble fraction $(538.6 \mathrm{mg}), n$-BuOH-soluble fraction $(131 \mathrm{mg})$ and $\mathrm{H}_{2} \mathrm{O}$-soluble fraction $(630.8 \mathrm{mg})$. The $\mathrm{CHCl}_{3}$-soluble fraction was chromatographed over Sephadex $\mathrm{LH}-20$ column eluted with $\mathrm{CH}_{2} \mathrm{Cl}_{2} / \mathrm{MeOH}, 1: 1$ and then silica gel column eluted with $n$-hexane/EtOAc, 7:3 to give compounds $\mathbf{1}(0.9 \mathrm{mg}), \mathbf{2}(0.8 \mathrm{mg})$ and $\mathbf{3}(1.2 \mathrm{mg})$.

The dried and powdered sample ST1375 $(1.3 \mathrm{~kg})$ was extracted as above to afford a crude EtOH extract (65.3 g). A portion $(25 \mathrm{~g}$ ) was liquid-liquid partitioned using same procedures described above. The resulting $\mathrm{CHCl}_{3}$ fraction was subjected to a conventional acid-base extraction to afford a basic $\mathrm{CHCl}_{3}$-soluble fraction (Fraction A, $343.7 \mathrm{mg}$ ) and a neutral $\mathrm{CHCl}_{3}$-soluble fraction (Fraction $\mathrm{B}, 11.2 \mathrm{~g}$ ). Fraction A was first gel filtered on a Sephadex LH-20 column eluted with $n$-hexane/ $\mathrm{CH}_{2} \mathrm{Cl}_{2} / \mathrm{MeOH}, 4: 3: 3$ to give four pooled fractions (A1-A4). Fraction A2 was subjected to a combination of silica gel open column chromatography and HPLC on a semi-preparative C18 column (Purospher column, $5 \mu \mathrm{m}, 25 \times 1 \mathrm{~cm}$ ) or silica gel preparative TLC to furnish $4(1.4 \mathrm{mg})$ and $7(0.9 \mathrm{mg})$. Fraction A4 (191.4 mg) was rechromatographed over silica gel open column eluted with $n$-hexane/EtOAc mixtures to give $5(3.1 \mathrm{mg})$. A part of the fraction B $(4 \mathrm{~g})$ was flash chromatographed on silica gel column to furnish six subfractions (B1-B6). Subfraction B2 (171.5 mg) was separated by $\mathrm{C} 18$ open column chromatography and then by silica gel preparative TLC with $\mathrm{CHCl}_{3} / \mathrm{MeOH}, 50: 1$ as eluent to furnish $8(3.4 \mathrm{mg}), \mathbf{9}(2.7 \mathrm{mg})$ and $\mathbf{6}(1.4 \mathrm{mg})$.

Structures of isolated compounds were established by the interpretation of their ${ }^{1} \mathrm{H}$ NMR spectra and comparison of data obtained with those published in the literature. The ${ }^{1} \mathrm{H}$ NMR spectroscopic data of the isolated compounds can be obtained free of charge from the corresponding author.

Acknowledgments The authors are thankful to the ICBG project (Grant No U01 TW000313) and the CNARP for financial support during the plant collections and the supply of chemicals critical to this 
study. Thanks are also due to the College of Pharmacy at The Ohio State University, USA and the Department of Chemistry and Virginia Tech Center for Drug Discovery, Virginia Tech, USA for facilitating the acquisition of the NMR spectra.

\section{Compliance with Ethical Standards}

Conflict of Interest The authors declare no conflict interest.

Open Access This article is distributed under the terms of the Creative Commons Attribution 4.0 International License (http:// creativecommons.org/licenses/by/4.0/), which permits unrestricted use, distribution, and reproduction in any medium, provided you give appropriate credit to the original author(s) and the source, provide a link to the Creative Commons license, and indicate if changes were made.

\section{References}

1. T.G. Hartley, Allertonia 8, 1-341 (2001)

2. E.N. Matu, Melicope madagascariensis (Baker) T.G. Hartley, ed. by G.H. Schmelzer and A. Gurib-Fakim. Prota11 (2): Medicinal Plants 2. PROTA, (Wageningen, Netherlands, 2013), p 193

3. I.S. Chen, H.F. Chen, M.J. Cheng, Y.L. Chang, C.M. Teng, I. Tsutomu, J.J. Chen, I.L. Tsai, J. Nat. Prod. 64, 1143-1147 (2001)

4. H. Rei-Sheu, D. Chano-Yih, W. Shang-Kwei, C. Tai-Tsung, Phytochemistry 35, 271-272 (1993)

5. H.T. Simonsen, Phytochem. Lett. 5, 371-375 (2012)

6. J. Gleye, C. Moulis, M.N. Doazan, Plant. Med. Phytother. 17, 92-95 (1983)
7. J. Pusset, J.L. Lopez, M. Pais, M.A. Neirabeyeh, J.M. Veillon, Planta Med. 57, 153-155 (1991)

8. S.S. Kang, W.S. Woo, Arch. Pharm. Res. 9, 11-13 (1986)

9. G.E. Jackson, W.E. Campbell, B. Davidowitz, Spectrosc. Lett. 23, 971-982 (1990)

10. T.H. Yang, S.T. Lu, S.J. Wang, T.W. Wang, J.H. Lin, I.S. Chen, Yakugaku Zasshi 91, 782-786 (1971)

11. F. Muyard, F. Bevalot, B. Laude, J. Vaquett, Phytochemistry 31, 1087-1089 (1992)

12. A.G. Valesi, E. Rodriguez, G.V. Velde, T.J. Mabry, Phytochemistry 11, 2821-2826 (1972)

13. Z. Shenghua, G. Youheng, W. Zhixiong, X. Rui, Zhongcaoyao 42, 1891-1893 (2011)

14. S.G. Li, H.Y. Tian, W.C. Ye, R.W. Jiang, Biochem. Syst. Ecol. 39, 64-67 (2011)

15. M.T. Fauvel, J. Gleye, C. Moulis, F. Blasco, E. Stanislas, Phytochemistry 20, 2059-2060 (1981)

16. I.L. Tsai, S.J. Wu, T. Ishikawa, H. Seki, S.T. Yan, I.S. Chen, Phytochemistry 40, 1562 (1995)

17. H.T. Simonsen, M.D. Larsen, M.W. Nielsen, A. Adsersen, C.E. Olsen, D. Strasberg, U.W. Smitt, J.W. Jaroszewski, Phytochemistry 60, 817-820 (2002)

18. L.K. Basco, S. Mitaku, A.L. Skaltsounis, N. Ravelomanantsoa, F. Tillequin, M. Koch, J. Le Bras, Antimicrob. Agents Chemother. 38, 1169-1171 (1994)

19. T.N. Bennett, M. Paguio, B. Gligorijevic, A.A. Kosar, E. Davidson, P.D. Roepe, Antimicrob. Agents Chemother. 48, 1807-1810 (2004)

20. E.M. Addo, H.B. Chai, A. Hymete, M.Y. Yeshak, C. Slebodnick, D.G.I. Kingston, L.H. Rakotondraibe, J. Nat. Prod. 78, 827-835 (2015) 